\title{
IDÉIAS
}

\section{Presidencialismo é a história do compadrio}

José Fogaça

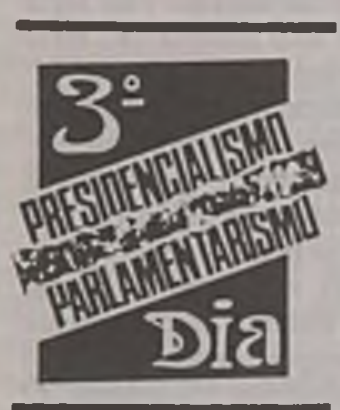

"No pouco tempo que devo utilizar para fazer a minha explanação, pretendo, antes de mais nada saudá-los pela iniciativa magnífica desse que é um dos mais operosos ativos e dignos ministros brasileiros, querido $\mathrm{Mi-}$ nistro Aluizio Alves. Porque esta é uma iniciativa que está de acordo com o momento político que estamos vivendo hoje no pais.

Com muita dignidade o Presidente da República declarou, na televisão, que ele, o Dr. José Sarney, enquanto cidadão, era favorável ao presidencialismo com um Congresso forte. Mas o fez, e isto foi clarificado de forma cabal, na condição de cidadão. No dia seguinte pela manhã, o Ministro Aluizio Alves, num canal de televisāo se declarava favorável ao parlamentarismo.

Isto demonstra que em nosso pais está instalado o debate político em torno dos sistemas de governo, num ambiente de liberdade, nun ambiente democrático, num ambiente aberto em que o próprio Presidente da República suscita o debate e os seus auxiliares são capazes de assumir posiçōes diferentes, no que tange ao sistema de governo.

Estamos numa Assembléia Nacional Constituinte. Em nosso pais tem sido reiterada e insistentemente dito que não se pode alterar o sistema de governo para superar crises e episódios. E esta é uma declaração, uma afirmação que resulta de uma experiência traumática que foi o único lapso de parlamentarismo do nosso período republicano.

Não sei, não conheço, não tenho registro e não posso sequer imaginar uma outra oportunidade mais propicia, mais conveniente, mais adequada para se mu-

José Fogaça Senador pelo PMDB do Rio Grande do Sul, e Debatedor do 3: Dia.

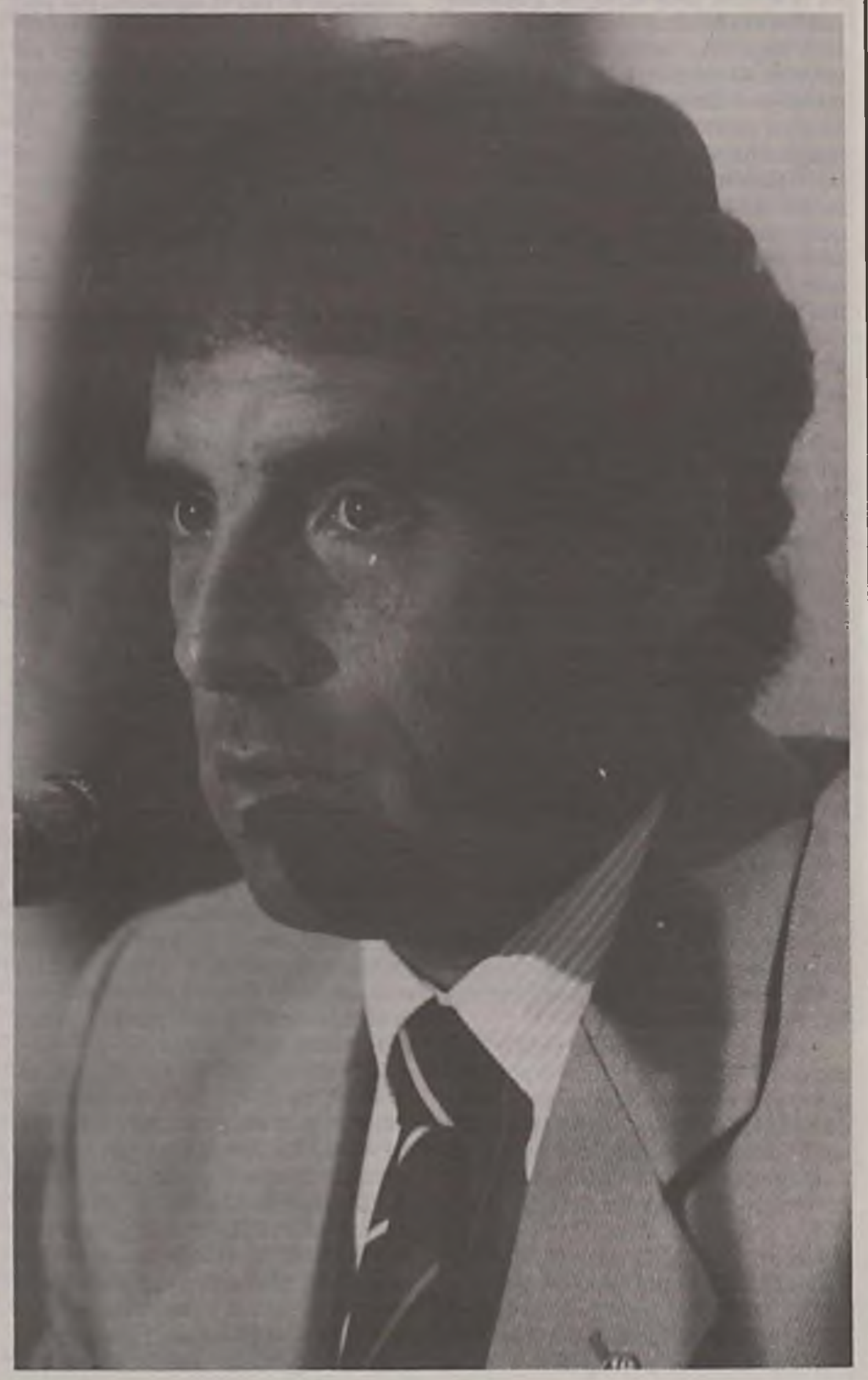




\section{IDÉIAS}

dar um sistema de governo que não seja a de uma Assembléia Nacional Constituinte.

Se alguém me for capaz de indicar um outro momento, uma outra situação, um outro contexto em que isso possa acontecer com mais legitimidade, a cederei. Mas, até agora na história dos povos, e principalmente na história dos povos livres, não há momento mais propicio, mais adequado do que aquele em que instalada e em pleno andamento uma Assembléia Nacional Constituinte.

$\mathrm{O}$ argumento que vem sendo levantado, que vem sendo erguido no Brasil de que qualquer mudança no sistema de governo seria a solução emergencial para a crise, na verdade é uin argumento retrógrado e conservador, que deseja erguer uma cortina de fumaça, erguer um biombo para mais uma vez impedir que o Brasil, caminhe na direção da sua modernidade. $\mathrm{E}$ isto não resulta só de conveniências ou de posicionamentos ideológicos. Resulta, muito mais não só de posicionamentos ideológicos, mas resulta muito mais, e isto sim, de conveniências políticas.

O nobre professor Uwe Thayssen citou aqui o extraordinário Max Weber. Foi o Max Weber quem disse que no presidencialismo a existência de um Congresso forte funciona, isto sim, como mecanismo inibidor e que o presidencialismo é incompativel com um Congresso forte, porque o Congresso passa a ser nada mais do que um antipoder, e que o único poder que possui é o poder inibitório, o poder da paralisia, o poder do bloqueio.

No Uruguai o fato de não ter sido votado ainda o orçamento, e no Uruguai o congresso é forte, o regime é presidencialista, o fato de não ter sido votado ainda o orçamento do ano passado está minando, dificultando e inibindo a ação politica do Presidente Sanguinetti.

No Equador a Assembléia Nacional Constituinte produziu um governo presidencialista onde o Presidente da República concentra nas suas mãos todos os poderes dos presidencialismos e todas as formas presidencialistas clássicas. No entanto foi conferido o extraordinário poder de fiscalização e controle ao Congresso equatoriano e o resultado tem sido trágico para a vida politico-institucional do Equador, de tal sorte que são tão eficientes os mecanismos inibitórios adotados pelo Congresso equatoriano em relação à ação po. lítica do Presidente que este se vê sistematicamente impedido de governar e o Equador vive a véspera permanente dos novos golpes.
Com todo o respeito àqueles que são defensores de um presidencialismo forte com um Congresso forte, eu fico com a opinião de Max Weber, que diz que isto leva necessariamente a existência de um antipoder.

E quem não recorda, neste nosso pais, dos últimos dois presidentes eleitos pelo voto direto, Jânio Quadros e Joāo Goulart. Esta frase foi cunhada por Jânio Quadros mais depois foi repetida por João Goulart: Jânio dizia que não podia governar porque o Congresso o impedia. Depois João Goulart disse a mesma coisa. Porque o Congresso Nacional, resultante da constituinte de 46 era um Congresso Nacional dotado de mecanismos extremamente eficazes de controle sobre o Poder Executivo.

\section{A necessidade de se dar uma nova estrutura à}

administração pública federal não é causa mais será efeito da implantação de um novo sistema de governo. É preciso ter partidos fortes $e$ burocracia estável para se instalar o parlamentarismo.

Disse eu no início desta explanação que muito bem procedeu o ministro Aluizio Alves, ao tomar a iniciativa deste conjunto de notáveis palestras com tão dignos professores de renome internacional.

A história do presidencialismo brasileiro tem sido no nivel da administração pública, e bem o sabe o ministro Aluízio Alves por que tem sido um dos combatedores mais contundentes destes vicios e destes defeitos. $A$ história do presidencialismo brasileiro tem sido no nivel da administração pública, a história do sistema do compadrio, do protecionismo, da sinecura, das benesses e das conveniências. E o lado oposto, a fase oposta do compadrio é a face da sabotagem. O sistema presidencialista gera esse Deus de dupla face na administração pública. Ou é uma adıninistração erigida em cima do paternalismo, do compadrio e dos vícios desse paternalismo ou então é uma administração emperrada pela dificuldade de administrar dada a sabotagem dos inimigos políticos instalados pelos adversários dos governantes.

A necessidade de dar eficiência, de dar uma nova estrutura à administração pública federal, não é causa mas será efeito da implantação de um novo sistema de governo. Assim como se dizia ao tempo do regime militar em que viveu o nosso país, que era preciso esperar que o povo aprendesse a votar para instalar a democracia, agora se diz que é preciso ter partidos fortes e burocratas estável para instalar o parlamentarismo. Não. A democracia o povo a aprende no seu exercicio, a democracia não é efeito da consciência popular, mas a democracia é causa do aprofundamento da consciência popular.

Da mesma forma e recordo aqui as palavras recentemente ditas aqui no Brasil, pelo Prof. Juan Lin, que aqui disse que partidos consistente e fortes e administração e burocracia estáveis e eficientes são efeitos e não causa de um sistema parlamentar de governo. Portanto, aquilo que é usado como argumento para impedir os avanços, as transformaçð̄es e a modernização de um sistema de governo para o nosso caso. A modernização das nossas instituiçōes, na verdade é um argumento em favor dessas teses renovadoras do nosso pais.

No Brasil os sistemas presidencialistas têm servido aos equivocos da esquerda e aos objetivos centrais da direita. E é preciso diferenciar bem o comportamento das esquerdas brasileiras. $O$ fato de ser esquerda no Brasil, nāo significa necessariamente que seja avançado ou moderno. Existe uma esquerda no Brasil que ainda está presa nos anos cinqüenta, é uma esquerda atrasada, de concepçōes arcaicas, baseada numa concepção populista e demagógica e numa visão golpista e apareIhista das reformas sociais, supondo que, bastará, através da relação direta de um salvador da pátria, de um semideus político, de um homem carismático, através de uma relação direta dele com o povo, bastará assentá-lo no trono presidencial para que a partir dali, de cima para baixo, ele realize toda as reformas sociais. $\mathrm{E}$ esta é uma visão golpista e aparelhista, porque basta, segundo esta concepção, tomar conta do aparelho do Estado, para a partir dele golpear as estruturas sociais nas formas estratificadas e injustas como 


\section{IDÉIAS}

elas se organizam na sociedade brasileira.

Pois esta visão aparelhista e golpista das esquerdas mais atrasadas e populistas deste país têm levado os nossos presidentes ou ao suicídio, ou à renúncia, ou à deposição pelas armas. Para a direita conservadora, o presidencialismo serve também por uma razão simples, porque nada é preciso mudar ou muito pouca coisa é preciso mudar para tirar um presidente civil eleito pelo voto direto e colocar no seu lugar um general ditador. Muito pouca coisa é preciso mudar. E é por isso que o presidencialismo serve à direita no nosso país.

Não fugiremos, tenho certeza, e posso aqui afirmar, a uma necessária reformulação das instituições políticas em nosso país através da Assembléia Nacional Constituinte. No entanto temos dois elementos com os quais temos que jogar, dos quais não podemos fugir nas diretrizes que orientarão esta reforma do sistema de governo em nosso país. $\mathrm{O}$ primeiro elemento é a cultura política do povo brasileiro no sentido de uma grande tradição, de uma forte raiz da figura do Presidente da República, eleito pelo voto direto.

Está é hoje uma realidade inescapável da vida brasileira. Mas muito mais do que a própria campanha das eleições diretas que transformou as multidōes em personagens centrais da vida brasileira no ano de 84 , muito mais do que isso, o que temos também como realidade é uma cultura política presidencialista. O Brasil não tem, em todos os niveis da sua sociedade, uma prática societária ou conseIhista de administração. Seja na associação de bairro tem um presidente que decide tudo. Seja num clube de futebol é um presidente que decide tudo. Seja no governo do estado, nas prefeituras municipais, em todos os níveis a nossa cultura política está arraigadamente presa a idéia de que o poder unipessoal é a solução para os problemas da populaçảo. Esta é uma questão da qual não podemos fugir, ou seja, existe como dado fundamental para qualquer reformulação do nosso sistema institucional, a necessidade de mantermos e muito mais do que mantermos, de assegurarmos ao povo brasileiro o direito de eleger, pelo sufrágio direto, secreto e universal o seu Presidente da República.

Mas de outro lado há também o anseio, há uma aspiração que se expressa também na sociedade brasileira, mas que agora emerge insupitavelmente nesta Assembléia Nacional Constituinte da qual somos membros orgulhosamente. Um an- seio, uma aspiração de que o Congresso Nacional, o parlamento deve se expressar não só enquanto Poder Legislativo, não só enquanto poder de fiscalização, mas também naquelas condições tão bem lembradas aqui pelo Prof. Uwe Tayssen no seu poder de iniciativa enquanto governo e enquanto articulação da sociedade. Este é um desejo que existe hoje notoriamente na Assembléia Nacional Constituinte. E por isso nos debates da subcomissão do poder executivo que tenho a honra de participar como relator, uma das decisões centrais tem sido a de que um Congresso forte, um Congresso participativo terá que necessariamente se expressar não só pelo poder de fiscalização, o poder inibitório, o poder de bloqueio, o antipoder de que falava Max Weber, mas terá que se expressar através da figura de

A questão da estabilidade política é encarada por nós como uma questão da maior importância dentro de um novo sistema de governo. E para isso criamos e produzimos mecanismos de estabilidade que são também novos na história dos povos.

um primeiro-ministro que seja dotado de poderes de governo que tenha a direção superior da administração pública federal, que tenha co-responsabilidade nas iniciativas das leis que elabore orçamento e o submeta ao Congresso Nacional e que dê provimento e extinção aos cargos públicos.

Não chegamos a essas conclusões por causa de questões emergenciais, episódicas ou conjunturais. Chegamos a essas conclusōes primeiro, é claro, em função da rica e múltipla experiência vivida pelos povos do mundo inteiro, principalmente os povos mais avançados. E sem xenofobia ou sem um nacionalismo primário e até facista, entendemos que é preciso colher essa experiência múltipla e rica das outras nações, que conseguiram atin- gir estágios superiores de governo, mas o que é o centro, o que é a base, o que é o eixo central dos nossos trabalhos na subcomissão do poder executivo que leva adiante a reformulação do sistema de governo no Brasil, não é a crise do momento, não é a momentosidade das nossas dificuldades mas é isto sim a rigorosa interpretação científica da história republicana e das múltiplas e frustradas experiências do nosso presidencialismo, que tem sido, ao longo da nossa vida republicana, a ante-sala dos golpes militares, e a antesala das longas noites de escuridão e ditadura.

É por isso que vamos caminhar na direção de um novo sistema de governo. Um regime de co-responsabilidade em que a possibilidade da co-habitação, de que nos Maurice Duverger, no seu livro, não estará fora de nosso horizonte político. Mas em que a co-habitação, que é uma etapa, que é uma experiência hoje vivida pela França, encontre no Brasil, mecanismos pelos quais o confronto e a crise possam ser superados por formas necessárias, compulsórias de negociação, de acordos políticos para produzir resultados e para produzir efeitos mais produtivos e estáveis.

A questão da estabilidade política é encarada por nós como uma questão da maior importância dentro de um novo sistema de governo. E para isso criamos e produzimos mecanismos de estabilidade que são também novos, que são inéditos nas experiências constitucionais dos povos civilizados e que por certo haveremos de, ao longo do tempo, aperfeiçoar na vida institucional brasileira.

Com tudo isto, acreditamos que daremos um passo adiante, que marcharemos na direção de um novo estágio para o nosso país. Não fazer isso significaria, seguramente, no limiar do terceiro milênio, na entrada de uma nova era da humanidade, no final do século XX seria retrocedermos às instituições retrógradas, não da velha república, mas da república velha, nos primórdios do período republicano brasileiro, como um figura central, poderosa, prepotente de um presidente manipulando um Congresso fraco e com poderes delimitados. Como não queremos retroceder às instituições do princípio do século, como não queremos reproduzir aqui as crises que marcaram 98 anos de história republicana, vamos avançar na direção de um novo sistema de governo que terá como base a busca da negociação, da co-responsabilidade, do acordo político e da estabilidade." 